\title{
Theoretical study of intramolecular hydrogen bonding in the halo derivatives of 1-amino-3-imino-prop-1-ene
}

\author{
SAEEDREZA EMAMIAN* and SAYYED FARAMARZ TAYYARI \\ Department of Chemistry, Shahrood Branch, Islamic Azad University, Shahrood, Iran \\ e-mail: s_emamian@iau-shahrood.ac.ir
}

MS received 6 November 2012; revised 11 April 2013; accepted 17 May 2013

\begin{abstract}
Intramolecular hydrogen bonding (IHB) of 1-amino-3-imino-prop-1-ene (AIP), as the simplest resonance-assisted hydrogen bond system in symmetric $\mathrm{N}-\mathrm{H} \cdots \mathrm{N}$ class, and its halo derivatives $(\mathrm{F}, \mathrm{Cl}$, and $\mathrm{Br}$ ) have been studied at the DFT-B3LYP/6-311++ $\mathrm{G}^{* *}$ level of theory. For better understanding of the nature of substituent effects, nitro and methoxy derivatives of AIP were also added to our consideration. Good linear correlations between IHB energies based on Espinosa's equation and $-G(r) / V(r)$ values, total electronic density, Laplacian of total electronic density in critical points, $\pi$-electron delocalization parameter $(Q)$, hyper conjugative interaction energy of $\mathrm{lp}(\mathrm{N}) \rightarrow \sigma^{*}(\mathrm{~N}-\mathrm{H}),\left(F_{i, j} / S_{i, j}\right)^{2}$ parameter, natural charges of bridged hydrogen, frequency shift of the $\mathrm{N}-\mathrm{H}$ stretching vibration, and chemical shift of bridged hydrogen were obtained.
\end{abstract}

Keywords. Intramolecular hydrogen bond; 1-amino-3-imino-prop-1-ene (AIM); density functional theory (DFT); natural bond orbital analysis (NBO).

\section{Introduction}

Hydrogen bond, for the first time, was suggested by Huggins in $1919 .{ }^{1}$ After this, large number of theoretical and experimental studies have been conducted to investigate the properties of intramolecular and intermolecular hydrogen bonding. ${ }^{2-6}$ This type of bond occurs in both inorganic molecules such as water and organic molecules such as DNA; and plays important roles in biological systems, biochemical reactions, transformation of genetic information, etc. ${ }^{7}$

In an intramolecular hydrogen bond (IHB) system, both proton donor and proton acceptor groups, which may be of various kinds of functional groups, are located in the same molecule. Interaction of these functional groups may result in a ring-like structure that is often referred to as chelated ring. The cis-enol forms of $\beta$-diketone, $\beta$-aminoenone, and $\beta$ enaminoimine molecules are engaged in such a hydrogen bond system and could be stabilized by a sixmembered chelated ring. ${ }^{8-10}$ Formation of IHB in these systems leads to an enhancement of resonance conjugation in the $\pi$-electron system. This kind of hydrogen bond was named by Gilli et al. ${ }^{11}$ as resonanceassisted hydrogen bond (RAHB). Formation of this kind of hydrogen bond causes an obvious affinity for

*For correspondence bond equalization of the valence bonds in the resulting chelated ring. Therefore, it seems that any parameter that affects the electron density of the chelating ring will change the hydrogen bond strength. By replacing the hydrogen atom in the $\alpha$-position $\left(\mathrm{R}^{2}\right.$ position in scheme 1$)$ or in the $\beta$-position $\left(\mathrm{R}^{1}\right.$ and $\mathrm{R}^{3}$ positions in scheme 1) with the electron-withdrawing groups, the strength of such a bridge decreases. ${ }^{12,13}$ Alkyl substitution at the $\alpha$-position of $\beta$-dicarbonyls causes an intense decrease in the enol content, while it increases the hydrogen bond strength. ${ }^{14}$ These effects of substituents other than alkyl groups are more complicated because of the competition between factors stabilizing or destabilizing the enol and keto groups. Electron-withdrawing groups tend to reduce hydrogen bond strength by increasing positive charges on the carbonyl oxygen atom. ${ }^{15-17}$ Finally, electron-withdrawing groups that are able to conjugate with the enol double bond increase the stability of the enol and strengthen its hydrogen bond. ${ }^{18,19}$

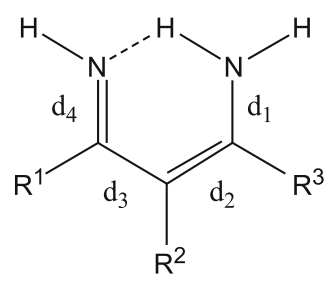

Scheme 1. The Gilli's parameters and substitution positions for 1-amino-3-imino-prop-1-enes. 
The complexity of these substituent effects in $\beta$ diketones is apparent when the sequence of enol contents on going from $\mathrm{Cl}$ to $\mathrm{Br}$ and to $\mathrm{I}$ is considered. A chloro substituent usually increases the enol content, but the enol content becomes smaller for $\mathrm{Br}$ and $\mathrm{I}$ because of the predominant stearic effects. According to the nuclear magnetic resonance (NMR) proton chemical shifts, the trend in IHB strength is $\alpha$-bromoacetylacetone $>$ acetylacetone $>$ $\alpha$-chloroacetylacetone. ${ }^{20}$ To the best of our knowledge, no such studies have been conducted on the IHB of halogen-substituted of $\beta$-enaminoimine (a chelated $\mathrm{N}-\mathrm{H} \cdot \cdots \mathrm{N}$ system) compounds. The simplest member of the RAHB intramolecular $\mathrm{N}-\mathrm{H} \cdot \cdots \mathrm{N}$ type is 1-amino3-imino-prop-1-ene (AIP) (scheme 1). Theoretically, there are three different positions for substitution of halogen atoms $(\mathrm{F}, \mathrm{Cl}$, and $\mathrm{Br})$ in the carbon skeleton of $\operatorname{AIP}\left(\mathrm{R}^{1}, \mathrm{R}^{2}\right.$ and $\mathrm{R}^{3}$ positions in scheme 1$)$.

We aim to study the IHB properties of $\alpha$ - and $\beta$ halo-substituted AIP. Therefore, substituent effects on the $\mathrm{H}$-bond strength, the $\pi$-electron delocalization, and the geometry of IHB system were studied. For such analysis, density functional theory (DFT) calculations and Bader's ${ }^{21}$ quantum theory of atoms in molecules (QTAIM) are applied. To obtain more information on the nature of the IHB; the natural bond orbital analysis (NBO), IR frequencies, and NMR chemical shifts were also considered. To obtain a better understanding of substitution effects, the effects of nitro and methoxy derivatives of AIP on the hydrogen bonding properties were also examined.

\section{Computational details}

Geometry optimizations and calculation of their electronic wave functions were performed for parent molecule (AIP) and its halo, nitro and methoxy derivatives in the gas phase at the B3LYP/6-311++ $\mathrm{G}^{* *}$ level, using Gaussian 09 software package. ${ }^{22}$ The AIM computations were carried out by using the AIM2000 program. ${ }^{23,24}$ In order to find vibrational $\mathrm{N}-\mathrm{H}$ stretching frequencies of the stationary points in RAHB systems under study, harmonic frequency calculations were performed at the same level of theory. The second-order interaction energies $\left(E^{2}\right)$, associated with hydrogen bonds, were calculated using NBO 5.0 program. ${ }^{25}$ For prediction of ${ }^{1} \mathrm{H}$ NMR chemical shift of the bridged hydrogen, NMR calculations were applied using gaugeindependent atomic orbital (GIAO) method ${ }^{26,27}$ at the B3LYP $/ 6-311++\mathrm{G}^{* *}$ level of theory. The predicted ${ }^{1} \mathrm{H}$ chemical shifts are derived from $\delta=\sigma_{\mathrm{o}}-\sigma$. In this equation, $\delta$ is the chemical shift, $\sigma$ is the absolute shielding of bridged hydrogen, and $\sigma_{\mathrm{o}}$ is the absolute shielding of hydrogen nuclei in TMS (tetra methylsilane) as reference.

Finally, correlations between some calculated parameters with IHB energies have also been considered. Graphs were drawn and regression analyses were performed using Microsoft Office Excel, 2010 software.

\section{Results and discussion}

\subsection{Basis of AIM and its analysis}

In the topological theory of AIM, when two neighbouring atoms are chemically bonded, a bond critical point appears between them and the nature of chemical bonds and molecular reactivity are described by total electronic density, $\rho(r)$, and its corresponding Laplacian, $\nabla^{2} \rho(r)$. Laplacian of total electronic density is related to energetic topological parameters by a local expression of the virial theorem at critical points: ${ }^{21}$

$$
\frac{1}{4} \nabla^{2} \rho(r)=2 G(r)+V(r),
$$

where $G(r)$ and $V(r)$ are the kinetic and potential electron energy densities at critical points, respectively. In the characterization of IHB, bond critical point (BCP) in the hydrogen bond and ring critical point (RCP) in the RAHB ring are useful. Positive values of $\nabla^{2} \rho(r)$ at BCP indicate that $G(r)$ is greater than that of $V(r)$ and shows depletion of electronic charge along the bond path, which is specification of closed-shell interactions such as hydrogen bonds, but negative values show excess potential energy at BCP which is the specialty of shared interactions, such as covalent bonds. In the later case, electronic charge is focused in the internuclear region and shared by two nuclei. ${ }^{28}$ As Rozas et al. ${ }^{29}$ explained; hydrogen bonds can be classified as follows:

- Weak hydrogen bonds $\left(E_{\mathrm{HB}}<12.0 \mathrm{kcal} / \mathrm{mol}\right)$ : $\nabla^{2} \rho\left(r_{\mathrm{BCP}}\right)>0$ and $G\left(r_{\mathrm{BCP}}\right)+V\left(r_{\mathrm{BCP}}\right)>0$;

- Medium hydrogen bonds $\left(12.0<E_{\mathrm{HB}}<24.0 \mathrm{kcal} / \mathrm{mol}\right)$ : $\nabla^{2} \rho\left(r_{\mathrm{BCP}}\right)>0$ and $G\left(r_{\mathrm{BCP}}\right)+V\left(r_{\mathrm{BCP}}\right)<0$;

- Strong hydrogen bonds $\left(E_{\mathrm{HB}}>24.0 \mathrm{kcal} / \mathrm{mol}\right)$ : $\nabla^{2} \rho\left(r_{\mathrm{BCP}}\right)<0$ and $G\left(r_{\mathrm{BCP}}\right)+V\left(r_{\mathrm{BCP}}\right)<0$;

where $G\left(r_{\mathrm{BCP}}\right)+V\left(r_{\mathrm{BCP}}\right)$ is also known as total electron energy density, $H\left(r_{\mathrm{BCP}}\right)$. The typical ranges of $\rho(r)$ and $\nabla^{2} \rho(r)$ for hydrogen bond in BCP are $0.002-0.035 \mathrm{e} / \mathrm{a}^{3}$ and $0.02-0.139 \mathrm{e} / \mathrm{a}_{\circ}^{5}$, respectively. ${ }^{30}$ The nature of IHB can be determined using ratio of $-G\left(r_{\mathrm{BCP}}\right) / V\left(r_{\mathrm{BCP}}\right)$, which for $-G\left(r_{\mathrm{BCP}}\right) / V\left(r_{\mathrm{BCP}}\right)>1$, the IHB has noncovalent nature, while for $0.5<-G\left(r_{\mathrm{BCP}}\right) / V\left(r_{\mathrm{BCP}}\right)<1$ is 
partly covalent. ${ }^{31}$ Prediction of IHB energy is one of the most important subjects in recent studies not only for its characterization, but also due to the role it plays in numerous processes such as for example, in hydration. Several theoretical methods ${ }^{32,33}$ have been proposed to estimate hydrogen bond energy. One of the most useful of these methods has been explained by Espinosa et al. ${ }^{34}$ who found that IHB energy may be correlated with the potential electron energy density at critical point by the expression $E_{\mathrm{IHB}}=1 / 2 V\left(r_{\mathrm{BCP}}\right)$. The calculated total electronic density and its corresponding Laplacian at bond critical point and ring critical point, potential electron energy density, kinetic electron energy density, ratio of $-G(r) / V(r)$ at bond critical point, and IHB energy are given in table 1. For comparison, the corresponding data for malonaldehyde (MA), reported by $\mathrm{Mo}^{35}$ are also listed in table 1 . According to this table, for all molecules under investigation, Laplacian of total electronic densities at BCPs are positive and reveal that electronic charges are depleted in the interatomic path, which is characteristic of closed shell interactions. It is also shown in table 1 that $-G(r) / V(r)$ values in all cases with the exception of halogenated and methoxy derivatives in $\mathrm{R}^{3}$ position and also MA are greater than unity and shows that hydrogen bonds are of noncovalent nature. On the other hand, this factor for halogenated and methoxy derivatives in $\mathrm{R}^{3}$ position is nearly unit and the partly covalent nature of hydrogen bonds can be concluded. The $-G(r) / V(r)$ ratio for MA is considerably less than unit. In cases, where this ratio is less than unit, the hydrogen bond energy is greater than $8.0 \mathrm{kcal} / \mathrm{mol}$. In the last column of table 1 , hydrogen bond energies calculated based on Espinosa's equation are presented. A closer look at these values clarifies that all IHB interactions investigated in this study, can be classified as weak ones except for MA. The IHB energies in the considered molecules can be explained from two aspects: (i) position of halogen substituent and (ii) halogen substituent effect. From position of halogen substituent point of view (respect to the parent molecule), it is clear that substitution of halogen atoms in $\mathrm{R}^{1}$ leads to a decrease in IHB energy; while in $\mathrm{R}^{3}$, it causes an increase in IHB energy. In $\mathrm{R}^{2}$ position, $\mathrm{Cl}$ and $\mathrm{Br}$ substituents have no significant effect on the strength of IHB, but $\mathrm{F}$ atom results in decrease in IHB energy. From halogen substituent effect point of view, hydrogen bonding strength in $\mathrm{R}^{2}$ and $\mathrm{R}^{3}$ positions is in order of $\mathrm{Br}>\mathrm{Cl}>\mathrm{F}$, while in $\mathrm{R}^{1}$ position it is in order of $\mathrm{Cl}>\mathrm{Br}>\mathrm{F}$. In the case of nitro derivatives, the strength of hydrogen bond for substitution in $\mathrm{R}^{1}$ and $\mathrm{R}^{2}$ positions decreases and increases with respect to the parent molecule, respectively. These results could be well-explained by considering the electron-withdrawing nature of $\mathrm{NO}_{2}$ group. However, substitution of $\mathrm{NO}_{2}$ group in $\mathrm{R}^{2}$ position considerably increases the hydrogen bond strength of AIP. In this case, the $\mathrm{NO}_{2}$ is coplanar with the chelated ring. The increase in hydrogen bond strength by $\mathrm{NO}_{2}$ substitution is very similar to that observed for nitromaloaldehyde. ${ }^{36}$ Two factors have been considered to account for this increase in hydrogen bond strength, taking part of nitro group in $\pi$-electron delocalization

Table 1. Topological parameters (in a.u) and IHB energies (kcal/mol) calculated on the B3LYP/ $6-311++G^{* *}$ wave functions.

\begin{tabular}{lcccccccr}
\hline $\mathrm{R}^{1}, \mathrm{R}^{2}, \mathrm{R}^{3}$ & $\rho_{\mathrm{N} \cdots \mathrm{H}}$ & $\nabla^{2} \rho_{\mathrm{N} \cdots \mathrm{H}}$ & $V(r)_{\mathrm{N} \cdots \mathrm{H}}$ & $G(r)_{\mathrm{N} \cdots \mathrm{H}}$ & $-G(r) / V(r)$ & $\rho_{\mathrm{RCP}}$ & $\nabla^{2} \rho_{\mathrm{RCP}}$ & $E_{\mathrm{IHB}}$ \\
\hline $\mathrm{H}, \mathrm{H}, \mathrm{H}$ & 0.0295 & 0.0972 & -0.0217 & 0.0230 & 1.0599 & 0.0134 & 0.0884 & 6.80 \\
$\mathrm{~F}, \mathrm{H}, \mathrm{H}$ & 0.0251 & 0.0864 & -0.0173 & 0.0195 & 1.1271 & 0.0130 & 0.0824 & 5.42 \\
$\mathrm{H}, \mathrm{F}, \mathrm{H}$ & 0.0260 & 0.0884 & -0.0182 & 0.0201 & 1.1043 & 0.0126 & 0.0816 & 5.71 \\
$\mathrm{H}, \mathrm{H}, \mathrm{F}$ & 0.0334 & 0.1020 & -0.0255 & 0.0255 & 1.0000 & 0.0141 & 0.0944 & 8.00 \\
$\mathrm{Cl}, \mathrm{H}, \mathrm{H}$ & 0.0258 & 0.0892 & -0.0181 & 0.0202 & 1.1160 & 0.0132 & 0.0840 & 5.67 \\
$\mathrm{H}, \mathrm{Cl}, \mathrm{H}$ & 0.0295 & 0.0976 & -0.0217 & 0.0230 & 1.0599 & 0.0134 & 0.0880 & 6.80 \\
$\mathrm{H}, \mathrm{H}, \mathrm{Cl}$ & 0.0353 & 0.1060 & -0.0278 & 0.0271 & 0.9748 & 0.0144 & 0.0972 & 8.72 \\
$\mathrm{Br}, \mathrm{H}, \mathrm{H}$ & 0.0254 & 0.0880 & -0.0176 & 0.0198 & 1.1250 & 0.0132 & 0.0840 & 5.52 \\
$\mathrm{H}, \mathrm{Br}, \mathrm{H}$ & 0.0297 & 0.0984 & -0.0220 & 0.0233 & 1.0590 & 0.0135 & 0.0884 & 6.90 \\
$\mathrm{H}, \mathrm{H}, \mathrm{Br}$ & 0.0357 & 0.1068 & -0.0283 & 0.0275 & 0.9717 & 0.0145 & 0.0980 & 8.87 \\
$\mathrm{NO}, \mathrm{H}, \mathrm{H}$ & 0.0257 & 0.0897 & -0.0180 & 0.0202 & 1.1222 & 0.0134 & 0.0853 & 5.66 \\
$\mathrm{H}, \mathrm{NO}, \mathrm{H}$ & 0.0331 & 0.1035 & -0.0255 & 0.0257 & 1.0078 & 0.0142 & 0.0941 & 7.99 \\
$\mathrm{H}, \mathrm{H}, \mathrm{NO} 2$ & 0.0302 & 0.0985 & -0.0224 & 0.0235 & 1.0491 & 0.0139 & 0.0908 & 7.03 \\
$\mathrm{MeO}, \mathrm{H}, \mathrm{H}$ & 0.0312 & 0.1012 & -0.0235 & 0.0244 & 1.0383 & 0.0141 & 0.0911 & 7.38 \\
$\mathrm{H}, \mathrm{MeO} . \mathrm{H}$ & 0.0282 & 0.0941 & -0.0204 & 0.0220 & 1.0776 & 0.0131 & 0.0854 & 6.39 \\
$\mathrm{H}, \mathrm{H}, \mathrm{MeO}$ & 0.0349 & 0.1063 & -0.0275 & 0.0270 & 0.9818 & 0.0143 & 0.0961 & 8.62 \\
$\mathrm{MA}$ & 0.0492 & 0.1351 & -0.0470 & 0.0404 & 0.8696 & 0.0198 & 0.1250 & 12.55 \\
\hline
\end{tabular}

${ }^{\mathrm{a}}$ Data from ref. 16 


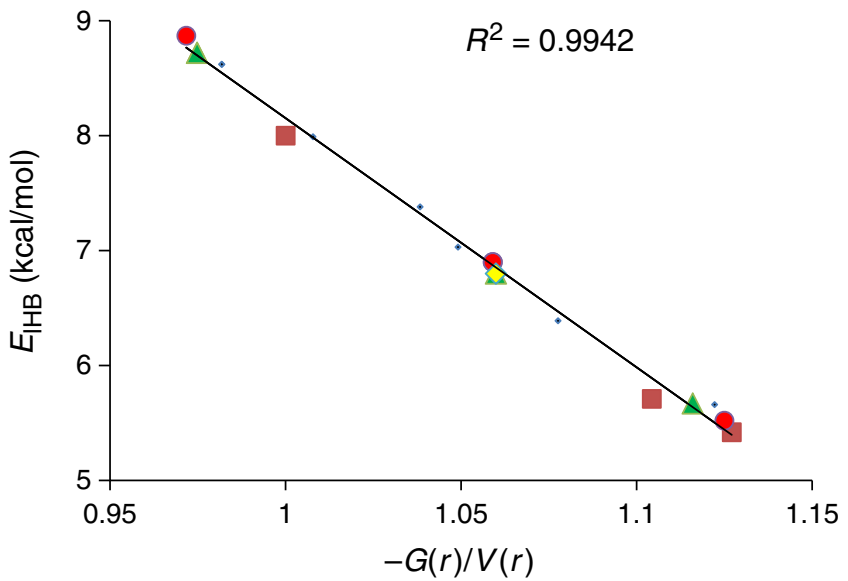

Figure 1. Linear correlation between IHB energies (kcal/ mol) and $-G(r) / V(r)$ values; $\mathbf{\square}, \mathrm{F}, \boldsymbol{\Lambda}, \mathrm{Cl} ; \bullet$, $\mathrm{Br} ; \bullet$, AIP.

with the chelated ring, which forces the $\mathrm{NO}_{2}$ group to be coplanar with the chelated ring, and the stearic effect, which also results from the planarity of the resultant molecule. However, for methoxy derivatives, where methoxy acts as an electron-releasing group, substitution in both $\mathrm{R}^{1}$ and $\mathrm{R}^{3}$ positions, increases hydrogen bond strength compared to the parent molecule. The electron-releasing nature of the methoxy group well explains the strength of substituted methoxy in $\mathrm{R}^{1}$ position. The increase of hydrogen bond strength in the $\mathrm{R}^{3}$ methoxy-substituted AIP is only explained by the high stearic effect of the methoxy group, which compensates for its electron-releasing effect. Therefore, increase in the hydrogen bond strength for the halo-derivatives of AIP in $\mathrm{R}^{3}$ position could be attributed to the stearic effects between the halogen atoms and free $\mathrm{H}$ atom of the amine group.

Earlier studies have shown that topological parameters in BCP and RCP may be useful to describe the strength of IHB. ${ }^{37-39}$ In figures 1 and 2, the correlation of IHB energies with $-G(r) / V(r)$ values at BCPs, total electronic density and its corresponding Laplacian in BCPs and RCPs are shown. The linear dependence with high regression coefficients (near to unit) indicates that there is strong correlation between IHB energies with $-G(r) / V(r)$ values (descriptor of IHB nature), total electronic density and its corresponding Laplacian in BCPs and RCPs. Consequently, in the RAHB systems with $\mathrm{N}-\mathrm{H} \cdots \mathrm{N}$ unit, these parameters are good descriptors for investigation of IHB energy. In correlation between IHB energy and $\rho \mathrm{N} \cdot \cdots \mathrm{H}$, figure 2(a), in spite of including the MA results, excellent correlation is observed, $R^{2}=0.997$ (by excluding the MA results $\left.R^{2}=0.9991\right)$. As shown in figure 2 , correlation IHB energy with $\rho_{\mathrm{RCP}}\left(R^{2}=0.8567\right)$ is not as good as with other topological parameters. Including the MA data does not considerably change the regression coefficient $\left(R^{2}=0.849\right)$.
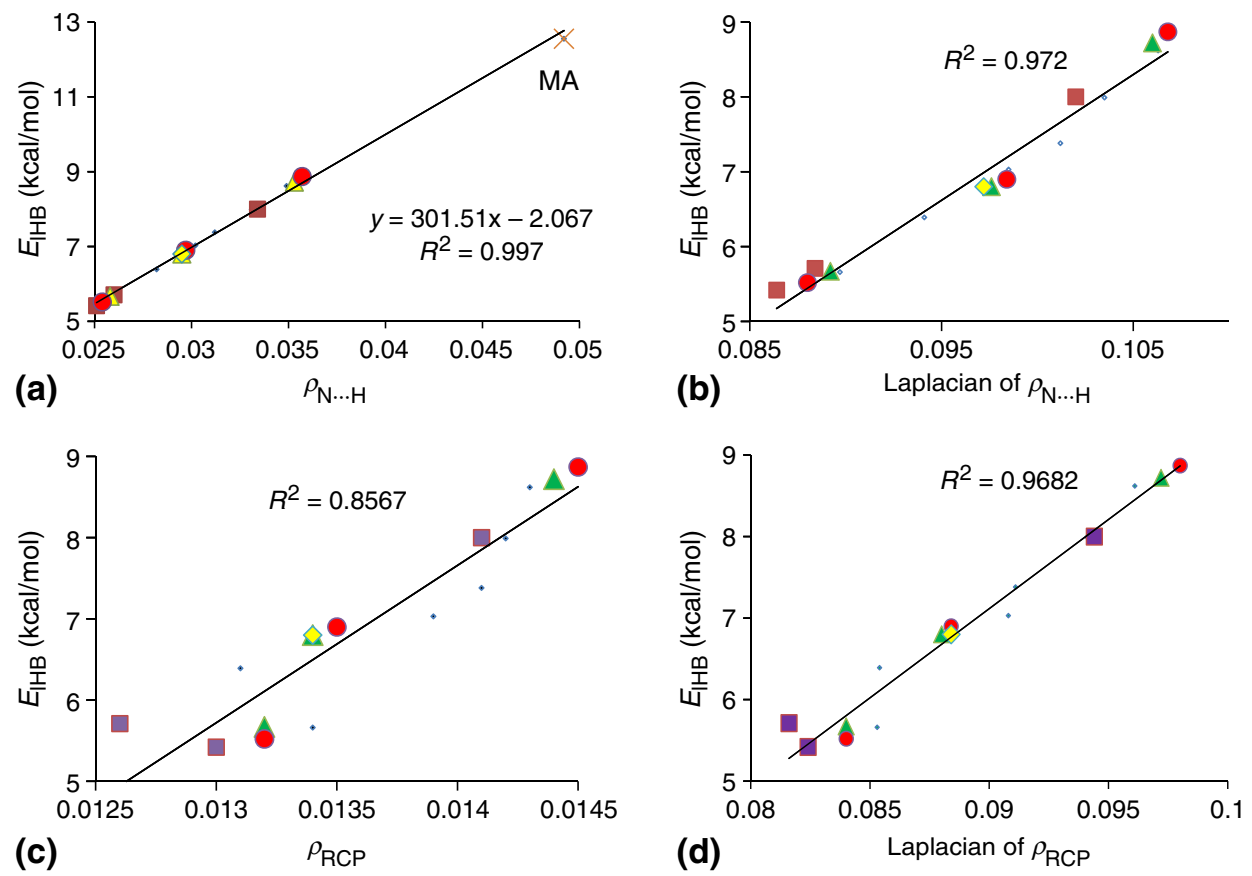

Figure 2. (a) Total electronic density at N...H BCP, (b) Laplacian of total electronic density at RCP, (c) total electronic density at RCP, and (d) Laplacian of total electronic density at RCP; $\mathbf{\square}, \mathrm{F}, \boldsymbol{\Delta}, \mathrm{Cl} ; \bullet, \mathrm{Br} ; \bullet$, AIP. 
Table 2. Selected geometrical parameters (distances in $\AA$ and angles in ${ }^{\circ}$ ) for AIP and its derivatives calculated at $\mathrm{B} 3 \mathrm{LYP} / 6-311++\mathrm{G}^{* *}$ level of theory.

\begin{tabular}{|c|c|c|c|c|c|c|c|c|}
\hline $\mathrm{R}^{1}, \mathrm{R}^{2}, \mathrm{R}^{3}$ & $d_{1}$ & $d_{2}$ & $d_{3}$ & $d_{4}$ & $r_{\mathrm{N} \cdots \mathrm{H}}$ & $r_{\mathrm{N} \cdots \mathrm{H}+\mathrm{H}-\mathrm{N}}$ & $r_{\mathrm{N}-\mathrm{N}}$ & $\angle \mathrm{N} \cdots \mathrm{H}-\mathrm{N}$ \\
\hline $\mathrm{H}, \mathrm{H}, \mathrm{H}$ & 1.347 & 1.367 & 1.437 & 1.295 & 1.969 & 2.989 & 2.733 & 129.4 \\
\hline $\mathrm{F}, \mathrm{H}, \mathrm{H}$ & 1.346 & 1.364 & 1.433 & 1.270 & 2.040 & 3.056 & 2.780 & 127.6 \\
\hline $\mathrm{H}, \mathrm{F}, \mathrm{H}$ & 1.354 & 1.357 & 1.432 & 1.292 & 2.028 & 3.045 & 2.775 & 128.1 \\
\hline $\mathrm{H}, \mathrm{H}, \mathrm{F}$ & 1.336 & 1.361 & 1.436 & 1.294 & 1.916 & 2.942 & 2.703 & 131.0 \\
\hline $\mathrm{Cl}, \mathrm{H}, \mathrm{H}$ & 1.345 & 1.366 & 1.435 & 1.271 & 2.029 & 3.045 & 2.765 & 127.1 \\
\hline $\mathrm{H}, \mathrm{Cl}, \mathrm{H}$ & 1.348 & 1.364 & 1.439 & 1.291 & 1.972 & 2.991 & 2.729 & 128.7 \\
\hline $\mathrm{H}, \mathrm{H}, \mathrm{Cl}$ & 1.340 & 1.365 & 1.438 & 1.294 & 1.888 & 2.916 & 2.691 & 132.4 \\
\hline $\mathrm{Br}, \mathrm{H}, \mathrm{H}$ & 1.345 & 1.367 & 1.434 & 1.268 & 2.036 & 3.052 & 2.769 & 127.0 \\
\hline $\mathrm{H}, \mathrm{Br}, \mathrm{H}$ & 1.347 & 1.365 & 1.440 & 1.291 & 1.967 & 2.986 & 2.725 & 128.8 \\
\hline $\mathrm{H}, \mathrm{H}, \mathrm{Br}$ & 1.340 & 1.365 & 1.439 & 1.294 & 1.883 & 2.912 & 2.689 & 132.7 \\
\hline $\mathrm{NO}_{2}, \mathrm{H}, \mathrm{H}$ & 1.343 & 1.370 & 1.424 & 1.271 & 2.028 & 3.045 & 2.769 & 127.6 \\
\hline $\mathrm{H}, \mathrm{NO}_{2}, \mathrm{H}$ & 1.329 & 1.379 & 1.446 & 1.289 & 1.922 & 2.947 & 2.699 & 130.1 \\
\hline $\mathrm{H}, \mathrm{H}, \mathrm{NO}_{2}$ & 1.337 & 1.361 & 1.442 & 1.291 & 1.962 & 2.983 & 2.723 & 129.1 \\
\hline $\mathrm{MeO}, \mathrm{H}, \mathrm{H}$ & 1.346 & 1.366 & 1.448 & 1.288 & 1.947 & 2.968 & 2.709 & 129.0 \\
\hline $\mathrm{H}, \mathrm{MeO} . \mathrm{H}$ & 1.354 & 1.365 & 1.440 & 1.294 & 1.991 & 3.010 & 2.750 & 129.1 \\
\hline $\mathrm{H}, \mathrm{H}, \mathrm{MeO}$ & 1.343 & 1.380 & 1.432 & 1.297 & 1.892 & 2.917 & 2.695 & 132.8 \\
\hline
\end{tabular}

\subsection{Geometrical and resonance analysis}

Geometrical parameters have various applications in the explanation of physico-chemical properties of IHB. Geometrical parameters of hydrogen bonds in the systems investigated here are presented in table 2 . We have considered the following parameters: $\mathrm{C}-\mathrm{N}(\mathrm{d} 1)$, $\mathrm{C}=\mathrm{C}(\mathrm{d} 2), \mathrm{C}-\mathrm{C}(\mathrm{d} 3), \mathrm{C}=\mathrm{N}(\mathrm{d} 4)$ bond lengths, $\mathrm{N} \cdots \mathrm{N}$, $\mathrm{N} \cdot \cdot \mathrm{H}$ distances, and $\mathrm{N} \cdots \mathrm{H}-\mathrm{N}$ angle. As illustrated in figure 3, the IHB energies correlate well with $r_{\mathrm{N} \cdots \mathrm{H}}$, $r_{\mathrm{N} \cdots \mathrm{N}}, r_{\mathrm{N} \cdots \mathrm{H}+\mathrm{H}-\mathrm{N}}$ distances and $\mathrm{N} \cdots \mathrm{H}-\mathrm{N}$ angle and the linear correlation coefficients are $0.9974,0.9578$, 0.9958, and 0.9141, respectively. As shown in figure 3, correlation of IHB energy with the sum of $\mathrm{N}-\mathrm{H}$ bond length and $\mathrm{N} \cdots \mathrm{H}$ distance is considerably better than the correlation between IHB energy and $\mathrm{N} \cdots \mathrm{N}$ distance. This result could be attributed to the non-linearity of the hydrogen bond system. According to table 2,
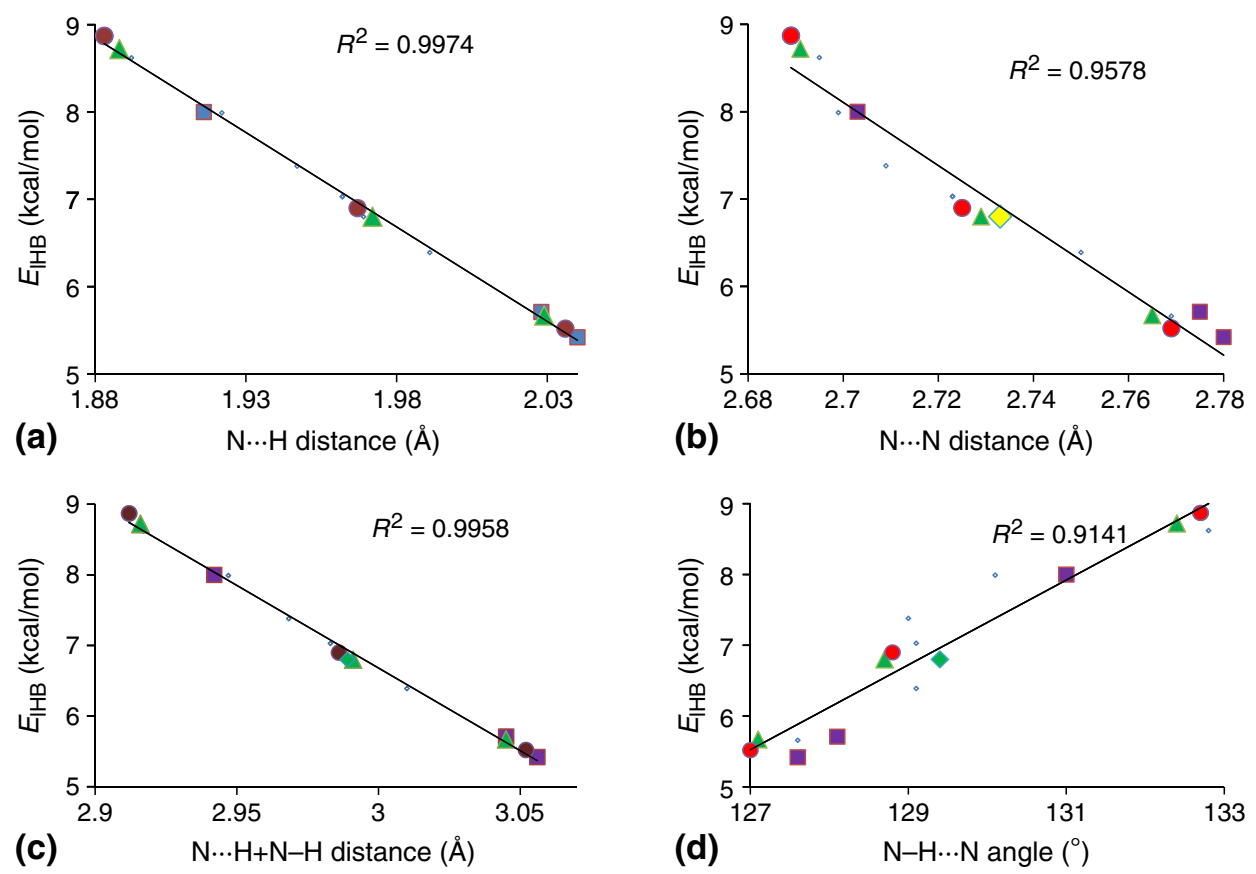

Figure 3. Linear correlation between IHB energies (kcal $/ \mathrm{mol}$ ) and (a) $\mathrm{N} \cdots \mathrm{H}$ distances $(\AA),\left(\right.$ b) $\mathrm{N} \cdots \mathrm{N}$ distances $(\AA),(\mathbf{c}) \mathrm{N} \cdots \mathrm{H}+\mathrm{H}-\mathrm{N}$ distances $(\AA)$, and $\mathrm{N} \cdots \mathrm{H}-\mathrm{N}$ angles $\left(^{\circ}\right)$; $\mathbf{\square}, \mathrm{F}, \boldsymbol{\Lambda}, \mathrm{Cl} ; \bullet, \mathrm{Br} ; \bullet$, AIP. 
Table 3. Values of $Q(\AA)$ and HOMA indices for AIP and its derivatives calculated at B3LYP/6-311+ $+\mathrm{G}^{* *}$ level of theory.

\begin{tabular}{lcc}
\hline $\mathrm{R}^{1}, \mathrm{R}^{2}, \mathrm{R}^{3}$ & $Q$ & HOMA \\
\hline $\mathrm{H}, \mathrm{H}, \mathrm{H}$ & 0.122 & 0.777 \\
$\mathrm{~F}, \mathrm{H}, \mathrm{H}$ & 0.145 & 0.733 \\
$\mathrm{H}, \mathrm{F}, \mathrm{H}$ & 0.137 & 0.763 \\
$\mathrm{H}, \mathrm{H}, \mathrm{F}$ & 0.117 & 0.767 \\
$\mathrm{Cl}, \mathrm{H}, \mathrm{H}$ & 0.143 & 0.731 \\
$\mathrm{H}, \mathrm{Cl}, \mathrm{H}$ & 0.132 & 0.748 \\
$\mathrm{H}, \mathrm{H}, \mathrm{Cl}$ & 0.119 & 0.767 \\
$\mathrm{Br}, \mathrm{H}, \mathrm{H}$ & 0.144 & 0.731 \\
$\mathrm{H}, \mathrm{Br}, \mathrm{H}$ & 0.131 & 0.745 \\
$\mathrm{H}, \mathrm{H}, \mathrm{Br}$ & 0.120 & 0.760 \\
$\mathrm{NO}, \mathrm{H}, \mathrm{H}$ & 0.126 & 0.801 \\
$\mathrm{H}, \mathrm{NO}{ }_{2}, \mathrm{H}$ & 0.107 & 0.730 \\
$\mathrm{H}, \mathrm{H}, \mathrm{NO}{ }_{2}$ & 0.127 & 0.722 \\
$\mathrm{MO}, \mathrm{H}, \mathrm{H}$ & 0.140 & 0.684 \\
$\mathrm{H}, \mathrm{MO} . \mathrm{H}$ & 0.135 & 0.745 \\
$\mathrm{H}, \mathrm{H}, \mathrm{MO}$ & 0.098 & 0.837 \\
\hline
\end{tabular}

the values of $r_{\mathrm{N} \cdots \mathrm{H}}, r_{\mathrm{N} \cdots \mathrm{N}}$ and $r_{\mathrm{N} \cdots \mathrm{H}+\mathrm{H}-\mathrm{N}}$ for each halogenated derivative reduce from $R^{1}$ to $R^{2}$ to $R^{3}$ positions. Additionally, the value of $\mathrm{N} \cdots \mathrm{H}-\mathrm{N}$ angle for each haloderivative has the highest value in the $\mathrm{R}^{3}$ position and the lowest value in $\mathrm{R}^{1}$ position. Also, table 2 shows that the $d 1, d 2, d 3$, and $d 4$ bond lengths are varied by substitution of halogens atoms, $\mathrm{NO}_{2}$, and methoxy groups at $\mathrm{R}^{1-3}$ positions. These bond length changes are attributed to changes in the $\pi$-electron delocalization of the RAHB ring. The corresponding bond equalization for the studied systems is the direct geometrical result of the $\pi$-electron delocalization. For the description of $\pi$-electron delocalization, the $Q$ parameter was introduced by Gilli and coworkers ${ }^{40}$ as follows:

$$
Q=(d 1-d 4)+(d 3-d 2),
$$

where $d 1, d 2, d 3$, and $d 4$ were sketched in scheme 1 . Table 3 illustrates that for halo and methoxy-derivative systems, the $Q$-parameter in the $\mathrm{R}^{1}$ and $\mathrm{R}^{2}$ positions are greater than that for parent molecule and the lowest values observed for the corresponding derivatives at the $\mathrm{R}^{3}$ position. A weak linear correlation for the Gilli's parameter, $Q$, with IHB energies is observed, $\mathrm{R}^{2}=0.6168$, (figure $4 \mathrm{a}$ ) and indicates that by increasing the IHB energies $\pi$-electron delocalization in the enaminoimine ring increases. However, the low regression coefficient for IHB energy correlation with $Q$ value indicates that $Q$ is not a good descriptor for IHB strength.

Another geometrical parameter for description of $\pi$-electron delocalization is harmonic oscillator measure of aromaticity (HOMA). This factor is defined in such a way to give 0 for a model non-aromatic system and 1 for a system in which full $\pi$-electron delocalization occurs
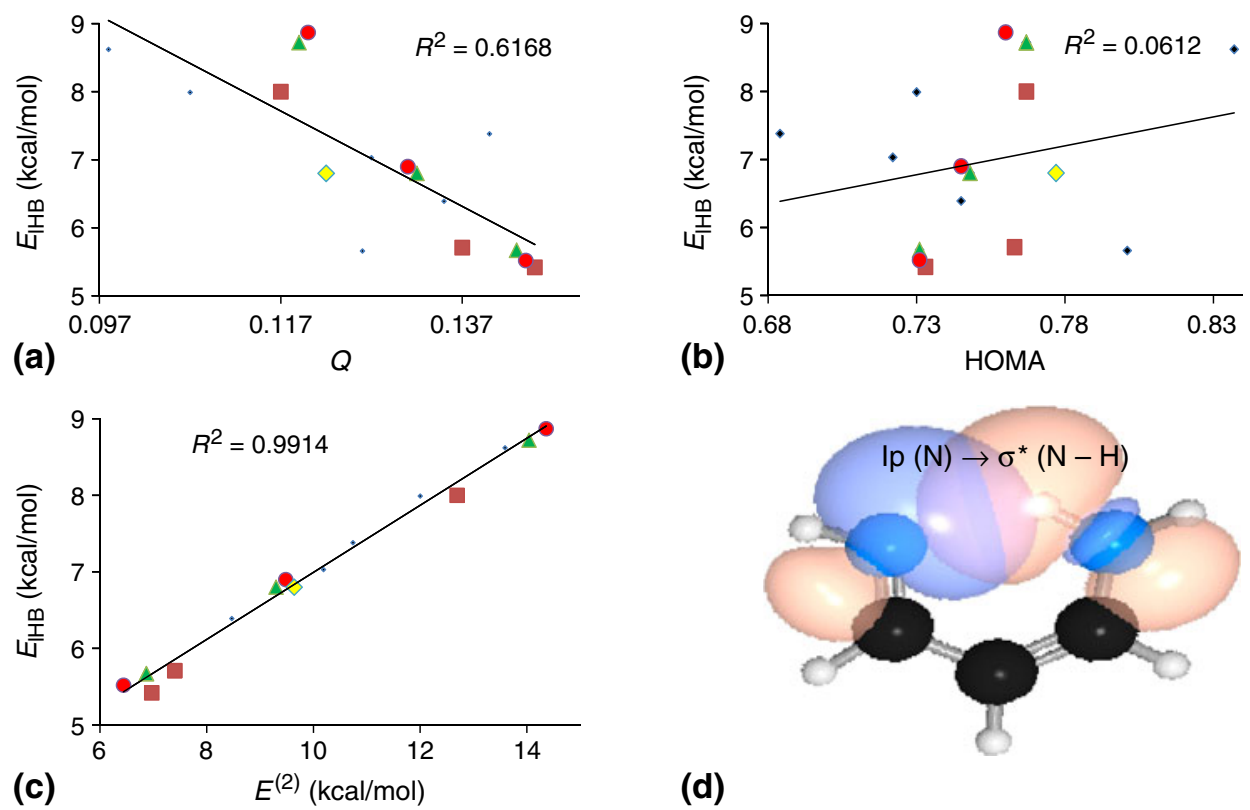

(d)

Figure 4. Linear correlation between IHB energies (kcal $/ \mathrm{mol})$ and (a) Gilli's coordinate, $Q$, (b) HOMA index, (c) perturbation interaction energies, $\left(E^{(2)}\right)$. $\mathbf{\square}, \mathrm{F}, \boldsymbol{\Delta}, \mathrm{Cl}$; • $\mathrm{Br} ; \diamond$, AIP. (d) 3D plot of preorthogonalized NBOs in IPA showing the most relevant $\operatorname{lp}(\mathrm{N}) \rightarrow \sigma^{*}(\mathrm{~N}-\mathrm{H})$ interaction. 
and all bonds are equal to the optimal value $R_{\mathrm{opt}, i}$. HOMA can be expressed by the following equation: ${ }^{41,42}$

$$
\mathrm{HOMA}=1-\frac{1}{n} \sum_{i=1}^{n} \alpha_{i}\left(R_{\mathrm{opt}, i}-R_{i}\right)^{2},
$$

where

$$
R_{\mathrm{opt}}=\frac{R_{(s)}+2 R_{(d)}}{3}
$$

and

$$
\alpha=\frac{2}{\left[R_{(s)}-R_{\mathrm{opt}}\right]^{2}+\left[R_{(d)}-R_{\mathrm{opt}}\right]^{2}} .
$$

In this equation, $\alpha$ is the normalization constant, $n$ is the number of bonds taken into account, $R_{\text {opt }}$ is the optimum bond length that is assumed to be realized when full delocalization of $\pi$ electrons occurs, and $R_{i}$ are the running bond lengths. $R_{(\mathrm{s})}$ and $R_{(\mathrm{d})}$ are optimal lengths of single and double bonds, respectively. In the present study, $R_{\mathrm{opt}, \mathrm{CC}}=1.388 \AA, R_{\mathrm{opt}, \mathrm{CN}}=1.334 \AA, \alpha_{\mathrm{CC}}=$ 257.70, and $\alpha_{\mathrm{CN}}=93.52$ were taken into account. ${ }^{43}$ As see in table 3 , in all halogenated derivatives of AIP, the aromaticity orders, based on HOMA index, are smaller than that for the parent molecule. On the other hand, aromaticity order for each halogenated system is $\mathrm{R}^{3}>\mathrm{R}^{2}>\mathrm{R}^{1}$. This order is the same for methoxy derivatives and it is in reverse direction for nitro-substituted AIPs. Additionally, our results show that there is no linear correlation between $E_{\mathrm{IHB}}$ and HOMA index in the studied molecules (figure 4b).

\subsection{NBO analysis}

Other method for characterization of IHB is hyperconjugative interaction and charge analysis based on NBO study. In Weinhold's NBO calculation, hyperconjugation has a stabilizing effect that arises from delocalization of electron density from filled (bonding or lone pair) Lewis type NBO to another neighbouring electron deficient orbitals (non-Lewis type NBO, such as antibonding or Rydberg) when these orbitals are properly oriented. For each donor NBO $(i)$ and acceptor NBO $(j)$, stabilization energy can be described by means of second-order perturbation interaction energy $\left(E^{(2)}\right)$ and estimated by the following equation:

$$
E^{(2)}=\Delta E_{i j}=q_{i} \frac{F(i, j)^{2}}{\varepsilon_{j}-\varepsilon_{i}},
$$

where $q_{i}$ is the donor orbital occupancy, $\varepsilon_{i}$ and $\varepsilon_{j}$ are diagonal elements (orbital energies) and $F(i, j)$ is the off-diagonal NBO Fock matrix elements. ${ }^{44}$ One of the important hyperconjugative interactions that is proportional to hydrogen bond strength, ${ }^{11}$ is $\operatorname{lp}(\mathrm{N}) \rightarrow \sigma^{*}(\mathrm{~N}-\mathrm{H})$, which is illustrated in figure 4(d). The value of this interaction for AIP and its derivatives is presented in table 4. Figure 4(c) indicates the variation of $E^{(2)}$ with IHB energy. According to table 4, the interaction energy between the $1 \mathrm{p}(\mathrm{N})$ and the $\sigma^{*}$ orbital of $\mathrm{N}-\mathrm{H}$ bond for all derivatives of AIP in $\mathrm{R}^{3}$, methoxyderivative in $\mathrm{R}^{1}$, and nitro-derivative in $\mathrm{R}^{2}$ positions are higher than that for the parent molecule which suggests that the IHB in these derivatives is stronger than that of the parent molecule. Excellent correlation between $E^{(2)}$ and IHB energies $\left(E_{\mathrm{HB}}\right), R^{2}=0.9914$, indicates excellent agreement between $E^{(2)}$ and IHP strength (figure $4 \mathrm{c}$ ). It is obvious that by increasing the $E^{(2)}$ energies, the IHB power increases, while non-covalent nature of IHB decreases (IHBs partly shift toward the covalent nature). Molecular stabilization due to IHB can also be evaluated from the overlap integrals for the attractive $\left(F_{i, j}\right)$ and repulsive $\left(S_{i, j}\right)$ interactions. The $\left(F_{i, j} / S_{i, j}\right)^{2}$ ratio is sometimes taken as a measure of the IHB stabilizing effect. ${ }^{3}$ The $\left(F_{i, j} / S_{i, j}\right)^{2}$ parameter was plotted versus IHB energies and a good dependency was observed (figure 5a). In order to further investigate the IHB in the molecules, the hydrogen atom which is directly involved in the IHB (bridged hydrogen) was analysed. Natural charges of bridged hydrogen are presented in table 3 and sketched against the IHB energies in figure 5(b). Linear relationship between natural charge and IHB energy implies that by increasing the acidic nature of bridged hydrogen (increasing in its positive natural charge), the IHB power increases.

Table 4. Natural charge on the bridged hydrogen $\left(q_{\mathrm{H}}\right)$ and

\begin{tabular}{|c|c|c|}
\hline $\mathrm{R}^{1}, \mathrm{R}^{2}, \mathrm{R}^{3}$ & $q_{\mathrm{H}}(\mathrm{C})$ & $E^{(2)}$ \\
\hline $\mathrm{H}, \mathrm{H}, \mathrm{H}$ & 0.437 & 9.64 \\
\hline $\mathrm{F}, \mathrm{H}, \mathrm{H}$ & 0.433 & 6.97 \\
\hline $\mathrm{H}, \mathrm{F}, \mathrm{H}$ & 0.435 & 7.40 \\
\hline $\mathrm{H}, \mathrm{H}, \mathrm{F}$ & 0.451 & 12.69 \\
\hline $\mathrm{Cl}, \mathrm{H}, \mathrm{H}$ & 0.432 & 6.87 \\
\hline $\mathrm{H}, \mathrm{Cl}, \mathrm{H}$ & 0.439 & 9.30 \\
\hline $\mathrm{H}, \mathrm{H}, \mathrm{Cl}$ & 0.450 & 14.04 \\
\hline $\mathrm{Br}, \mathrm{H}, \mathrm{H}$ & 0.430 & 6.44 \\
\hline $\mathrm{H}, \mathrm{Br}, \mathrm{H}$ & 0.439 & 9.48 \\
\hline $\mathrm{H}, \mathrm{H}, \mathrm{Br}$ & 0.450 & 14.36 \\
\hline $\mathrm{NO}_{2}, \mathrm{H}, \mathrm{H}$ & 0.433 & 6.87 \\
\hline $\mathrm{H}, \mathrm{NO}_{2}, \mathrm{H}$ & 0.444 & 12.00 \\
\hline $\mathrm{H}, \mathrm{H}, \mathrm{NO}_{2}$ & 0.450 & 10.19 \\
\hline $\mathrm{MeO}, \mathrm{H}, \mathrm{H}$ & 0.440 & 10.74 \\
\hline $\mathrm{H}, \mathrm{MeO}, \mathrm{H}$ & 0.434 & 8.47 \\
\hline $\mathrm{H}, \mathrm{H}, \mathrm{MeO}$ & 0.447 & 13.59 \\
\hline
\end{tabular}
perturbation interaction energies, $E^{(2)},(\mathrm{kcal} / \mathrm{mol})$ for AIP and its derivatives calculated at B3LYP $/ 6-311++\mathrm{G}^{* *}$ level of theory. 

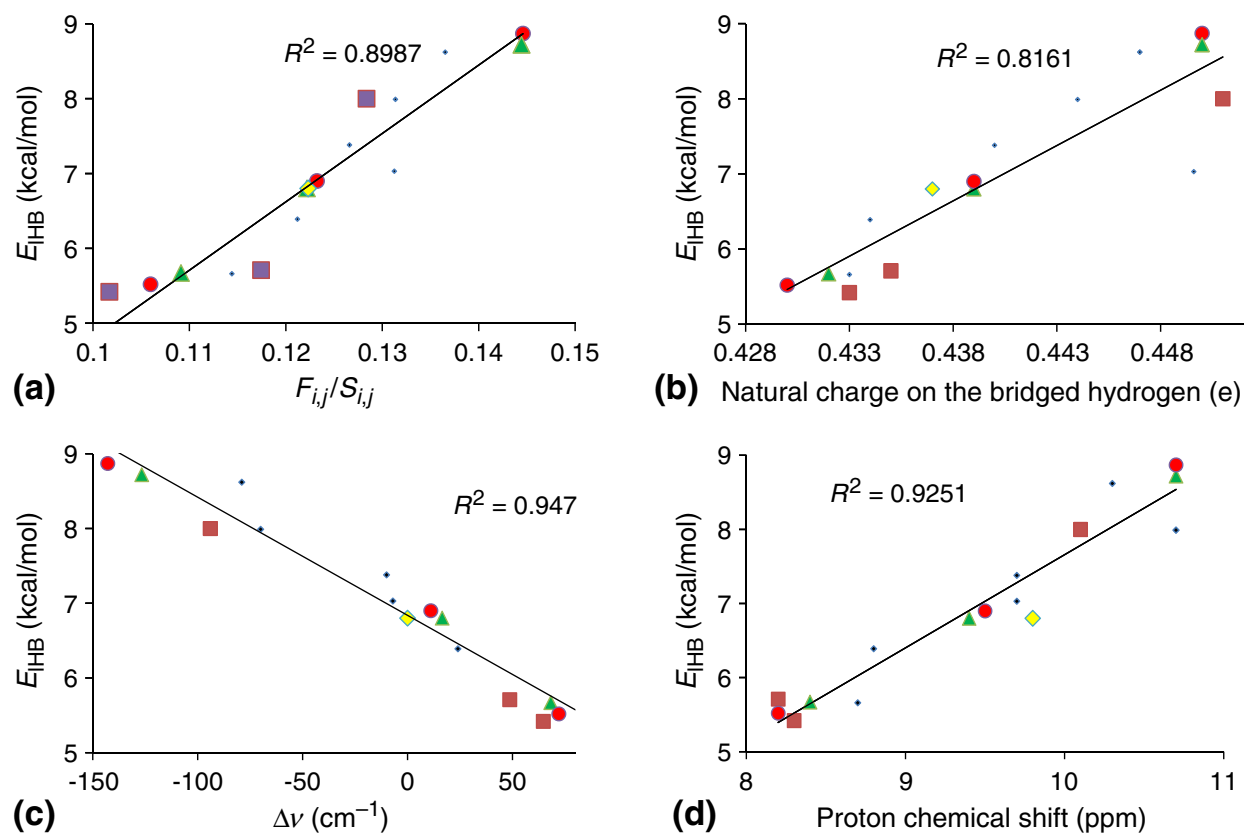

(b) Natural charge on the bridged hydrogen (e)

Figure 5. (a) Linear correlation between IHB energies $(\mathrm{kcal} / \mathrm{mol})$ and (a) $F_{i, j} / S_{i, j}$; (b) natural charge on the bridged $\mathrm{H}$ atom, $(\mathbf{c}) \mathrm{N}-\mathrm{H}$ stretching shift $\Delta v\left(\mathrm{~cm}^{-1}\right)$, and $(\mathbf{d})$ proton chemical shift (ppm); $\mathbf{\square}, \mathrm{F}, \boldsymbol{\Delta}, \mathrm{Cl} ; \bullet, \mathrm{Br} ; \diamond, \mathrm{AIP}$.

\subsection{IR and NMR analysis}

Infrared spectroscopy plays an important role in characterization of the nature of IHBs. ${ }^{3,45}$ The correlation between frequency shift of the $\mathrm{N}-\mathrm{H}$ stretching vibration, $\Delta v(\mathrm{~N}-\mathrm{H})$, and the IHB power is well-known and can be used for the estimation of IHB strength. ${ }^{34}$ The calculated frequency shifts of $\mathrm{N}-\mathrm{H}$ stretching vibration mode for parent molecule and its derivatives are tabulated in table 5 and plotted against IHB energies in figure 5(c). In substituted molecules at $\mathrm{R}^{1}$ and $\mathrm{R}^{2}$ positions, $v(\mathrm{~N}-\mathrm{H})$ mode shows a positive frequency shift (blue shift) and a negative frequency shift (red shift) in $\mathrm{R}^{3}$ position. The highest red shift observed for bromine substituent which is in agreement with the highest IHB power for bromine derivative in $\mathrm{R}^{3}$ position and the lowest red shift in $\mathrm{R}^{3}$ substituted derivative is observed for nitro substituent. As illustrated in figure 5(c), the IHB energies correlate well with $\Delta v(\mathrm{~N}-\mathrm{H})$. The larger negative shift shows higher IHB strength and larger positive shift shows lower IHB power. Another sensitive tool for measuring the IHB energy is the proton chemical shift $(\delta)$ of the bridged hydrogen atom. ${ }^{46}$ Formation of the IHBs leads, as a rule, to deshielding of bridged hydrogen atom and consequently to an increase in its chemical shift. Proton chemical shifts of parent molecule and its derivatives are tabulated in table 5 and graphically plotted versus IHB energies in figure 5(d).
The calculated proton chemical shifts for all derivatives of AIP in the $\mathrm{R}^{1}$ and $\mathrm{R}^{2}$ positions are upfield and downfield for $\mathrm{R}^{3}$ position, compared to parent molecule. According to the above explanations, it is clear that the bridged hydrogen in the substituent molecules at $\mathrm{R}^{1}$ and

Table 5. Frequency and frequency shift of $\mathrm{N}-\mathrm{H}$ stretching vibrational mode $\left(\mathrm{cm}^{-1}\right)$ and ${ }^{1} \mathrm{H}$ chemical shift $(\delta, \mathrm{ppm})$ of bridged hydrogen for AIP and its derivatives calculated at B3LYP/6-311 $++\mathrm{G}^{* *}$ level of theory.

\begin{tabular}{lccr}
\hline $\mathrm{R}^{1}, \mathrm{R}^{2}, \mathrm{R}^{3}$ & $v(\mathrm{~N}-\mathrm{H})$ & $\Delta v(\mathrm{~N}-\mathrm{H})^{*}$ & $\delta$ \\
\hline $\mathrm{H}, \mathrm{H}, \mathrm{H}$ & 3397 & - & 9.8 \\
$\mathrm{~F}, \mathrm{H}, \mathrm{H}$ & 3462 & 64.7 & 8.3 \\
$\mathrm{H}, \mathrm{F}, \mathrm{H}$ & 3446 & 48.7 & 8.2 \\
$\mathrm{H}, \mathrm{H}, \mathrm{F}$ & 3303 & -94.0 & 10.1 \\
$\mathrm{Cl}, \mathrm{H}, \mathrm{H}$ & 3466 & 68.3 & 8.4 \\
$\mathrm{H}, \mathrm{Cl}, \mathrm{H}$ & 3414 & 16.5 & 9.4 \\
$\mathrm{H}, \mathrm{H}, \mathrm{Cl}$ & 3271 & -126.7 & 10.7 \\
$\mathrm{Br}, \mathrm{H}, \mathrm{H}$ & 3469 & 72.1 & 8.2 \\
$\mathrm{H}, \mathrm{Br}, \mathrm{H}$ & 3408 & 11.1 & 9.5 \\
$\mathrm{H}, \mathrm{H}, \mathrm{Br}$ & 3254 & -142.9 & 10.7 \\
$\mathrm{NO}, \mathrm{H}, \mathrm{H}$ & 3461 & 94 & 8.7 \\
$\mathrm{H}, \mathrm{NO}, \mathrm{H}$ & 3327 & -70 & 10.7 \\
$\mathrm{H}, \mathrm{H} . \mathrm{NO}{ }_{2}$ & 3390 & -7 & 9.7 \\
$\mathrm{MeO}, \mathrm{H}, \mathrm{H}$ & 3387 & -10 & 9.7 \\
$\mathrm{H}, \mathrm{MeO}, \mathrm{H}$ & 3421 & 24 & 8.8 \\
$\mathrm{H}, \mathrm{H}, \mathrm{MeO}$ & 3318 & -79 & 10.3 \\
\hline
\end{tabular}


$\mathrm{R}^{2}$ positions is shielded and at $\mathrm{R}^{3}$ position is deshielded which is in good agreement with natural charges of bridged hydrogen and IHB energies. Also, there is a linear equation with high regression coefficient between proton chemical shifts and IHB energies (figure 5d).

\section{Conclusion}

The geometries of IPA and its halo, nitro, and methoxy derivatives are optimized at the B3LYP/6-311++ $\mathrm{G}^{* *}$ level of theory. Delocalization of $\pi$-electrons in the quasi-aromatic system arise from existence of IHB, the topological parameters derived from the theory of Bader, geometrical parameters, and vibrational and NMR spectroscopy can be used to estimate the IHB power. All these techniques imply that substitution at $\mathrm{R}^{1}$ position, except for methoxy, because of its strong electron donating nature, reduces the hydrogen bond strength. Substitution of $\mathrm{F}$ atom, an electronwithdrawing group, and methoxy, an electro-donating group, at $\mathrm{R}^{2}$ position decreases the IHP strength, while substitution of $\mathrm{Cl}$ and $\mathrm{Br}$ at this position does affect the IHB strength much. Increasing IHP power at $\mathrm{R}^{2}$ position by $\mathrm{NO}_{2}$ group is attributed to the resonance effect.

The strength of IHB in all $\mathrm{R}^{3}$ substituted derivatives is higher than that of parent molecule. This result is attributed to the stearic effect. Increase in the hydrogen bond in $\mathrm{NO}_{2}$ substituted derivative at $\mathrm{R}^{3}$ position is partly compensated by its strong electron-withdrawing nature. Therefore, substitution of $\mathrm{NO}_{2}$ at $\mathrm{R}^{3}$ position shows lowest increase in the hydrogen bond strength among all other substituted derivatives.

\section{References}

1. Huggins M L 1919 Thesis, University of California

2. Fuster F and Grabowski S J 2011 J. Phys. Chem. A 115 10078

3. Lopes Jesus A J and Redinha J S 2011 J. Phys. Chem. A 11514069

4. Zahedi-Tabrizi M and Farahati R 2011 Comp. Theor. Chem. 977195

5. Bende A 2010 Theor. Chem. Acc. 125253

6. Vakili M, Tayyari S F, Kanaani A, Nekoei A R, Salemi S, Miremad H, Berenji A R and Sammelson R E 2011 J. Mol. Struct. 99899

7. Ebrahimi A, Habibi Khorasani S M and Neyband R S 2010 Int. J. Quantum. Chem. 1101871

8. Vakili M, Nekoei A-R, Tayyari S F, Kanaani A and Sanati N 2012 J. Mol. Struc. 1021102

9. Berenji A R, Tayyari S F, Rahimizadeh M, Eshghi H, Vakili M and Shiri A 2013 Spectrochim. Acta A 102350
10. Gilli G and Gilli P 2009 The nature of hydrogen bond (Oxford: Oxford University Press)

11. Gilli G, Bellucci F, Ferretti V and Bertolasi V 1989 J. Am. Chem. Soc. 1111023

12. Zahedi-Tabrizi M, Tayyari F, Moosavi-Tekyeh Z, Jalali A and Tayyari S F 2006 Spectrochim. Acta $\mathbf{A 6 5}$ 387

13. Tayyari S F, Milani-Nejad F and Rahemi H 2002 Spectrochim. Acta 58A 1669

14. Emsley J 1984 Struct. Bond. (Berlin) 57147

15. Tayyari S F, Najafi A, Emamian S, Afzali R and Wang Y A 2008 J. Mol. Struct. 878 10-21

16. Zahedi-Tabrizi M, Tayyari F, Moosavi-Tekyeh Z, Jalali A and Tayyari S F 2006 Spectrochim. Acta $\mathbf{A 6 5}$ 387

17. Tayyari S F, Milani-Nejad F and Rahemi H 2002 Spectrochim. Acta 58A 1669

18. Tayyari S F, Milani-Nejad F and Butler I S 2001 Vibr. Spectrosc. 26187

19. Tayyari S F, Moosavi-Tekyeh Z, Zahedi-Tabrizi M, Eshghi H, Emampour J S, Rahemi H and Hassanpour H 2006 J. Mol. Struct. 782191

20. Burdett J L and Rogers M T 1964 J. Am. Chem. Soc. 86 2105

21. Bader R F W 1990 Atoms in molecules. A quantum theory (Oxford: Oxford University Press)

22. Frisch M J et al. 2009 Gaussian 09, Revision A.02-SMP, Gaussian, Inc., Wallingford CT

23. Biegler-König F and Schönbohm J AIM2000 Version 2.0

24. Bader R F W, Tang Y H, Tal Y, Biegler-König F W 1982 J. Am. Chem. Soc. 104946

25. Glendening E D, Badenhoop J K, Reed A E, Carpenter J E, Bohmann J A, Morales C M and Weinhold F, Theoretical Chemistry Institute, University of Wisconsin, Madison, WI 2001 (http://www.chem.wisc.edu/ nbo5)

26. McWeeny R 1962 Phys. Rev. 1261028

27. London F 1937 J. Phys. Radium 8397

28. Pakiari A H and Eskandari K 2006 J. Mol. Struct. (THEOCHEM) $\mathbf{7 5 9} 51$

29. Rozas I, Alkorta I and Elguero J 2000 J. Am. Chem. Soc. 12211154

30. Ebrahimi A, Roohi H, Habibi M and Mohammadi M and Vaziri R 2006 Chem. Phys. 322289

31. Shainyan B A, Chipanina N N, Aksamentova T N, Oznobikhina L P, Rosentsveig G N and Rosentsveig I B 2010 Tetrahedron 668551

32. Schuster P, Zundel G and Sandrafy C 1976 The hydrogen bond (Amsterdam: North Holland Publ. Co.)

33. Nowroozi A, Raissi H and Farzad F 2005 J. Mol. Struct. (THEOCHEM) 730161

34. Espinosa E, Molins E and Lecomte C 1998 Chem. Phys. Lett. 285170

35. Mo Y 2012 J. Phys. Chem. 1165240

36. Tayyari S F, Moosavi-Tekyeh Z, Zahedi-Tabrizi M, Eshghi H, Emampour J S, Rahemi H and Hassanpour M 2006 J. Mol. Struct. 782191

37. Wojtulewski S and Grabowski S J 2003 J. Mol. Struct (THEOCHEM) $\mathbf{6 2 1} 285$

38. Quiñonero D, Frontera A, Ballester P, Garau C, Costa A and Deyá P M 2001 Chem. Phys. Lett. 39369

39. Grabowski S J 2002 Monatsch. Chem. 1331373 
40. Gilli P, Ferretti V, Bertolasi V and Gilli G $1991 \mathrm{~J}$. Am. Chem. Soc. 1134917

41. Krygowski T M 1993 J. Chem. Inf. Comput. Sci. 33708

42. Cyranski M K and Krygowski T M 1996 J. Chem. Inf. Comput. Sci. 361142

43. Krygowski T M and Cyranski M K 2001 Chem. Rev. 101 1385
44. Weinhold F and Landis C R 2005 A natural bond orbital donor-acceptor perspective (New York: Cambridge University Press)

45. Sobczyk L, Grabowski S J and Krygowski T M 2005 Chem. Rev. 1053513

46. Trendafilova N, Bauer G and Mihaylov T 2004 Chem. Phys. 30295 